\title{
Differences between smokers and never-smokers in sensitivity to nicotine: a preliminary report
}

\author{
OVIDE F. POMERLEAU, M. HARIHARAN, CYNTHIA S. \\ POMERLEAU, OLIVER G. CAMERON \& SALLY K. GUTHRIE
}

Behavioral Medicine Program, Department of Psychiatry, University of Michigan School of Medicine, 475 Market Place, Suite L, Ann Arbor, MI 48108, USA

\begin{abstract}
Sensitivity to nicotine was explored using test doses administered via intra-nasal aerosol in 10 smokers and 10 never-smokers. Smokers received $1.50 \mathrm{mg}$ nicotine (in 2 sprays, < 5 seconds apart, one spray per nostril); never-smokers received either $0.50 \mathrm{mg}(\mathrm{n}=3)$ or $0.25(\mathrm{n}=7)$ nicotine. Accumulation of nicotine in plasma, per unit dose administered, was nearly four times greater in never-smokers, than in smokers, indicating differences in pharmacokinetic tolerance. To examine sensitivity to nicotine without this confound, peak physiological reactivity (heart rate and blood pressure changes) was divided by peak plasma nicotine increment and the ratio was expressed as a function of cotinine level prior to dosing, thereby relating sensitivity to nicotine to history of exposure. In smokers, functional sensitivity to nicotine was inversely related to customary nicotine intake, replicating previous findings for light and heavy smokers. The observation that never-smokers were not much more sensitive to nicotine than light smokers is notable given the disparity in previous history of exposure.
\end{abstract}

\section{Introduction}

Several noninvasive methods for administering controlled doses of nicotine in a manner that mimics the sharp rise and fall of plasma nicotine from cigarette smoking have recently been developed (see review by Pomerleau, Pomerleau \& Rose, 1989). Such methods render it feasible and ethical to administer nicotine safely to neversmokers as well as to smokers who exhibit different smoking patterns, enabling a more systematic exploration of the phenomenon of

Correspondence to: Ovide F. Pomerleau, Behavioral Medicine Program, 475 Market Place, Suite L, Ann Arbor, MI 48108, USA. sensitivity to nicotine than has previously been possible at the human level. Not only can the dose and the pharmacokinetics of the nicotine delivery system be manipulated more readily than for cigarette smoking, but the potentially confounding contributions of the thousand or more compounds in tobacco smoke are eliminated.

The present study, designed primarily as a test of the safety of an intranasal nicotine aerosol administration device, provided an opportunity to examine physiological sensitivity to a single, punctate dose of nicotine. Both smokers and lifetime non-smokers were included as subjects, permitting assessment of the contribution of 
chronic tolerance (using plasma cotinine as an index of customary nicotine intake and hence an indirect index of chronic tolerance.) Because nicotine administration via aerosol was novel for both smokers and never-smokers, the contributions of behavioural tolerance and habituation to the dosing vehicle were minimized. Based on previous investigations of tolerance to nicotine (e.g. Perkins et al., 1989; Pomerleau, Fertig \& Shanahan, 1983), our expectations were that heavy smokers would show less sensitivity (i.e. greater functional tolerance) to nicotine than light smokers, and, by extension, that neversmokers would be more sensitive to nicotine than smokers.

\section{Subjects and methods}

Subjects were 20 healthy male and female smokers and lifetime non-smokers between the ages of 21 and 40, recruited from the general community and paid for their participation. Smokers ( 5 male, 5 female) were required to have smoked $>15$ cigarettes per day of a brand delivering $<0.5 \mathrm{mg}$ nicotine by FTC analysis for at least 3 years, and to score $>6$ on the Fagerstrom Tolerance Questionnaire (FTQ). Never-smokers (5 male, 5 female) had to report no sustained use of tobacco products (except for brief exposure followed by rejection of cigarette smoking). Smoking status was corroborated by plasma cotinine determination.

\section{Apparatus and assays}

The construction of the Intra-nasal Nicotine Aerosol Delivery Device (INADD) and preparation of the nicotine solution have been described in detail elsewhere (Pomerleau et al., 1992a). The device is designed to administer a dose consisting of two $50 \mu \mathrm{l}$ sprays (7 psi for 1 second), one spray into each nostril, in less than 5 seconds. Heart rate and blood pressure were obtained using a Mennen EKG monitor, Series 700 , and a Healthdyne autosphygmomanometer, model BP203NA. Plasma nicotine and cotinine concentrations were determined by a slight modification of the high performance liquid chromatographic (HPLC) method of Hariharan, VanNoord \& Greden (1988).

\section{Procedure}

All subjects participated in a screening session in which the study was explained and informed consent obtained. They were then familiarized with the procedure via the administration of two sprays of sterile $0.9 \% \mathrm{NaCl}$ from a spray dispenser, one to each nostril.

Testing was conducted in the morning at the University of Michigan Clinical Research Center. In order to establish a uniform deprivation interval prior to testing, smokers were told to smoke a cigarette upon arrival, half an hour before the session. After baseline physiological assessment and blood sampling, the subject signaled readiness to receive an administration, placed the nosepiece of the airbrush into the nose, and sniffed sharply (drawing in air into nose) coincident with delivery of the aerosol. An initial pair of sprays (containing $0.05 \mathrm{mg}$ nicotine, an ultra-low dose intended to be physiologically inert) was administered to all subjects as a training procedure; the actual test dose of nicotine was given 0.5 hours later. Blood samples for nicotine and cotinine and physiological measures (heart rate, systolic and diastolic blood pressure) were taken before and after the training dose, before and after the test doses, every 5 minutes thereafter until 25 minutes after the test dose, and a final sample 55 minutes after the test dose.

Safety testing was first conducted with ten smokers. For these subjects, a $1.50 \mathrm{mg}$ nicotine test dose was administered with minimal discomfort or difficulty. Subsequently, three never-smokers received a $0.50 \mathrm{mg}$ nicotine test dose and each complained of dizziness and some nausea after about 15 minutes. As a consequence, for the remaining seven never-smokers, the test dose was halved, to $0.25 \mathrm{mg}$ nicotine; no discomfort or difficulty was observed in these subjects.

\section{Results}

Mean age of smokers was $28.6 \pm 4.8$ years and mean Body Mass Index $\left(\mathrm{kg} / \mathrm{m}^{2}\right)$ was $22.8 \pm 1.5$. Mean age of never-smokers was $27.5 \pm 4.8$ years and mean Body Mass Index $\left(\mathrm{kg} / \mathrm{m}^{2}\right)$ was $22.5 \pm 2.7$. There was no significant differences between males and females, or between smokers and never-smokers, for either of these variables. For the smokers, mean cotinine level was $271.0 \pm 110.0 \mathrm{ng} / \mathrm{ml}$ and mean FTQ score was 

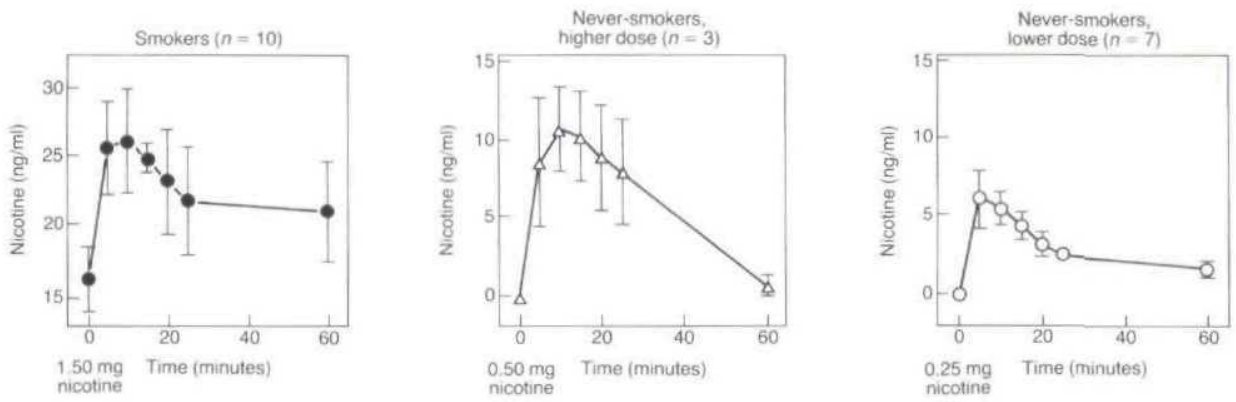

Figure 1. Mean plasma nicotine $\pm S E M$ over time following administration of a fixed dose of nicotine via intra-nasal aerosol. Left panel, 10 smokers with $1.50 \mathrm{mg}$ nicotine; middle panel, 3 never-smokers dosed with 0.50 mg nicotine; right panel, 7 never-smokers dosed with $0.25 \mathrm{mg}$ nicotine.

$8.5 \pm 1.6$. Never-smokers had a mean cotinine level of $1.4 \pm 2.4 \mathrm{ng} / \mathrm{ml}$. (Three had measurable cotinine values suggestive of passive exposure to cigarette smoke.)

In smokers, the change in plasma nicotine after the ultra-low nicotine dose was -1.6 $\mathrm{ng} / \mathrm{ml}$, a falling level consistent with decay of nicotine concentration following abstinence from cigarettes. For the ten never-smokers, a plasma nicotine increment of $+1.3 \mathrm{ng} / \mathrm{ml}$ was observed. Subjects were somewhat reactive to the training sprays. For the smokers, peak change in heart rate (mean $\pm \mathrm{sem}$ ) was $8.0 \pm 2.8 \mathrm{bpm}$, change in systolic blood pressure was $4.8 \pm 4.3 \mathrm{mmHg}$, and change in diastolic blood pressure was $2.7 \pm 1.8$ $\mathrm{mmHg}$; for the never-smokers, peak change in heart rate was $10.6 \pm 3.5 \mathrm{bpm}$, change in systolic blood pressure was $10.6 \pm 2.4 \mathrm{mmHg}$, and change in diastolic blood pressure was $6.7 \pm 2.0$ $\mathrm{mmHg}$. The $+1.3 \mathrm{ng} / \mathrm{ml}$ increase in plasma nicotine concentration and the somewhat greater physiological reactivity observed in never-smokers suggests that the ultra-low dose may not have been low enough to be completely inert for this group; in all cases, however, plasma nicotine levels had returned to zero before the administration of the subsequent nicotine dose.

The time course for plasma nicotine is shown in Fig. 1. The $1.50 \mathrm{mg}$ nicotine dose in smokers (starting from a baseline mean of $16.5 \mathrm{ng} / \mathrm{ml}$ ) produced a peak plasma nicotine increment of $11.5 \mathrm{ng} / \mathrm{ml}$. For the three subjects who received the $0.50 \mathrm{mg}$ dose, the peak nicotine increment, $12.0 \mathrm{ng} / \mathrm{ml}$, was about the same as that found for smokers despite a lower dose; for the seven who got the $0.25 \mathrm{mg}$ dose, peak nicotine increment was $7.5 \mathrm{ng} / \mathrm{ml}$. Plasma nicotine increment per unit dose (ratio of peak plasma nicotine level in $\mathrm{ng} / \mathrm{ml}$ to dose administered in $\mathrm{mg}$ ) was $7.69 \pm 1.51 \mathrm{ng} / \mathrm{ml} / \mathrm{mg}$ in smokers and $28.08 \pm 3.88 \mathrm{ng} / \mathrm{ml} / \mathrm{mg}$ in never-smokers; the difference in accumulation of nicotine between smokers and never-smokers was highly statistically significant $[t(11.65)=4.90, \quad p<0.000]$. There were no significant gender differences for plasma nicotine increment.

As shown in Table 1, peak physiological reactivity to nicotine was comparable for the ten smokers who received the $1.50 \mathrm{mg}$ dose of nicotine and the seven non-smokers who received the $0.25 \mathrm{mg}$ dose; the greatest physiological reactivity was exhibited by the three non-smokers who received the $0.50 \mathrm{mg}$ dose of nicotine. Peak heart rate reactivity either preceded the plasma nicotine peak $(50 \%$ of smokers and $60 \%$ of never-smokers) or coincided with it (20\% of smokers and $30 \%$ of never-smokers).

Sensitivity per unit nicotine increment (peak change in physiological reactivity divided by peak change in plasma nicotine) was calculated for each subject, and the resulting ratio was expressed as a function of baseline plasma cotinine level (see Fig. 2). In smokers, sensitivity to nicotine was inversely related to plasma cotinine level: Pearson correlation coefficients were $-0.69(p=0.028)$ for heart rate, -0.82 $(p=0.004)$ for systolic blood pressure, and -0.48 (NS) for diastolic blood pressure. (When data for the lowest-cotinine smoker were removed, correlations in the remaining $n$ of 9 remained negative $(-0.41,-0.59$, and -0.15 respectively) but did not reach significance.

Comparison of sensitivity to nicotine between smokers and never-smokers did not reveal 
Table 1. Plasma nicotine increment and peak physiological change (means \pm SD)

\begin{tabular}{|c|c|c|c|c|c|}
\hline & \multicolumn{2}{|c|}{ Nicotine } & \multirow[b]{2}{*}{$\begin{array}{l}\text { Heart rate } \\
\text { (bpm) }\end{array}$} & \multicolumn{2}{|c|}{ Blood pressure } \\
\hline & $\begin{array}{l}\text { Dose } \\
\text { (mg) }\end{array}$ & $\begin{array}{l}\text { Plasma } \\
\text { (ng/ml) }\end{array}$ & & $\begin{array}{l}\text { Systolic } \\
\text { (mm Hg) }\end{array}$ & $\begin{array}{l}\text { Diastolic } \\
(\mathrm{mm} \mathrm{Hg})\end{array}$ \\
\hline $\begin{array}{l}\text { Smokers } \\
(n=10)\end{array}$ & 1.50 & $\begin{array}{r}11.5 \\
\pm 7.2\end{array}$ & $\begin{array}{r}16.4 \\
\pm 6.3\end{array}$ & $\begin{array}{r}17.4 \\
\pm 6.7\end{array}$ & $\begin{array}{r}13.5 \\
\pm 9.1\end{array}$ \\
\hline $\begin{array}{l}\text { Never-smokers } \\
(n=3)\end{array}$ & 0.50 & $\begin{array}{r}12.0 \\
\pm 5.8\end{array}$ & $\begin{array}{r}37.3 \\
\pm 23.6\end{array}$ & $\begin{array}{r}24.3 \\
\pm 11.9\end{array}$ & $\begin{array}{r}10.3 \\
\pm 11.7\end{array}$ \\
\hline $\begin{array}{l}\text { Never-smokers } \\
(n=7)\end{array}$ & 0.25 & $\begin{array}{r}7.5 \\
+3.3\end{array}$ & $\begin{array}{r}17.1 \\
\pm 10.9\end{array}$ & $\begin{array}{r}21.6 \\
\pm 7.0\end{array}$ & $\begin{array}{r}9.3 \\
\pm 6.0\end{array}$ \\
\hline
\end{tabular}

highly-pronounced group differences. For heart rate, peak reactivity per unit plasma nicotine increment (mean $\pm \mathrm{sem}$ ) was $1.85 \pm 0.35 \mathrm{bpm} / \mathrm{ng}$ in smokers and $2.69 \pm 1.29 \mathrm{bpm} / \mathrm{ng}$ in neversmokers $[t(18)=1.55, \mathrm{NS}]$; for systolic blood pressure, peak reactivity per unit plasma nicotine increment was $1.91 \pm 0.35 \mathrm{mmHg} / \mathrm{ng}$ in smokers and $2.84 \pm 0.331 \mathrm{mmHg} / \mathrm{ng}$ in never-smokers $[t(18)=1.92$, NS $]$; for diastolic blood pressure, peak reactivity per unit plasma nicotine was $1.39 \pm 0.24 \mathrm{mmHg} / \mathrm{ng}$ in smokers and $1.13 \pm 0.30 \mathrm{mmHg} / \mathrm{ng}$ in never-smokers $[t(18)=-0.67, \mathrm{NS}]$.

In a more conservative analysis, an ANCOVA was conducted on physiological change scores using plasma nicotine boost as a covariate. No significant differences emerged for heart rate $[\mathrm{F}(1,17)=2.50, \mathrm{NS}]$ or diastolic blood pressure $[\mathrm{F}(1,17)=0.44, \mathrm{NS}] ;$ a marginally significant difference emerged for systolic blood pressure $[F(1,17)=4.45, p=0.05]$. (Note that for heart rate, the group differences are almost entirely accounted for by the three never-smokers who experienced nausea; see Table 1).

\section{Discussion}

Never-smokers exhibited a plasma nicotine pattern of rise and decay similar to that of smokers, but the magnitude of the peak (expressed as plasma level per unit dose administered) was nearly four times as large. This disparity in plasma nicotine accumulation between neversmokers and smokers is consistent with a report by Srivastava et al. (1991), who observed plasma nicotine concentrations in never-smokers that were twice those in smokers following application of $30 \mathrm{mg}$ transdermal nicotine patches (presumably having identical bioavailability).
Our preliminary interpretation of these findings is as follows: The distributional half-life of nicotine in current smokers is estimated to vary from 2 to $9 \mathrm{~min}$ (Feyerabend, Ings \& Russell, 1985). In the present study, since nicotine via aerosol was administered in less than $5 \mathrm{sec}-$ onds, differences in the rapid distributional phase between smokers and non-smokers may have significantly affected peak plasma nicotine observed in venous blood (in samples taken 5 and 10 minutes later). For example, in the study by Feyerabend et al. (1985), nicotine levels were measured 2 minutes after rapid intravenous injection of a fixed dose of nicotine to smokers: Plasma nicotine increments showed coefficients of variation of $61 \%$, and similarly large betweensubject variation in initial distribution volume $(57 \%)$ was observed; however, a much smaller variability in distributional half-life $(13 \%)$ was found. It is possible, therefore, that smokers exhibited a smaller peak change in plasma than never-smokers in the present study because they have a greater initial volume of distribution, and that the heavy instantaneous administration of nicotine in the present procedure exaggerated these distributional differences.

An alternative explanation, that smokers may clear nicotine more rapidly, is supported by reports indicating faster nicotine metabolism in smokers compared with non-smokers (Becket, Gorrod \& Jenner, 1971; Kyerematen et al., 1982; USDHAA, 1988). Furthermore, Benowitz $(1990$, p. 14) has noted that, even when bioavailability is fully controlled, there can be up to fourfold differences in the rate of nicotine metabolism among individual smokers. Finally, the possibility that nicotine bioavailability may differ between smokers and never-smokers cannot be ruled out at present-smokers may simply 

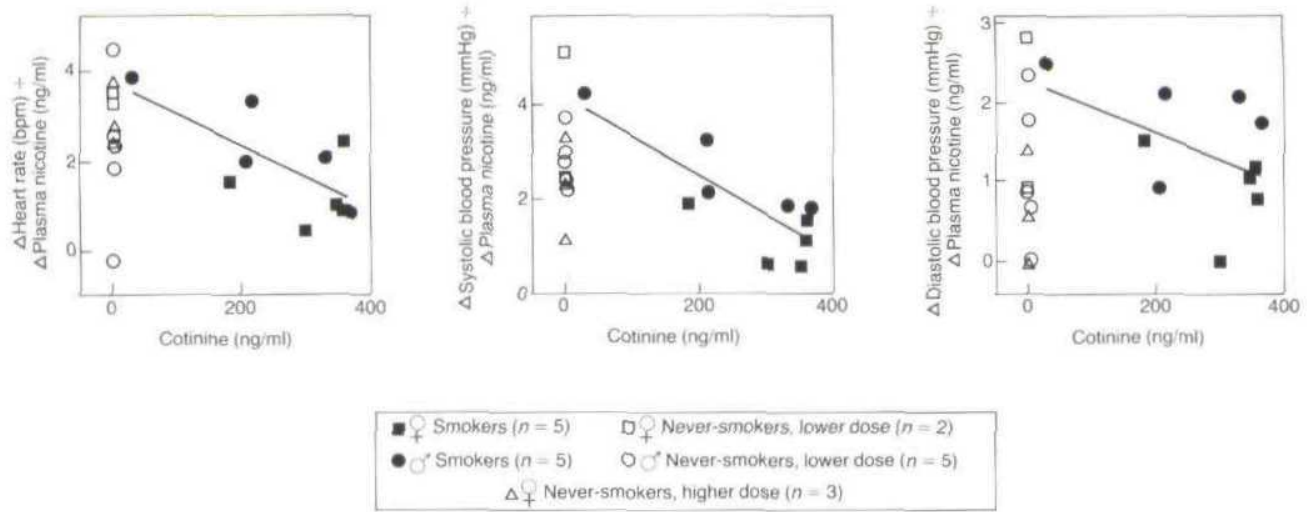

Figure 2. Mean physiological reactivity (peak increment) per unit plasma nicotine (peak increment) for 10 smokers and 10 never-smokers as a function of plasma cotinine. Regression lines for smokers: left panel, heart rate $(\mathrm{y}=3.7517-0.0070 x)$; middle panel, systolic pressure $(y=4.1582-0.0083 x)$; right panel, diastolic pressure $(y=2.2793-0.0033 x)$.

absorb less nicotine than non-smokers (e.g. because of inefficiency of nicotine transfer in the nasal mucosa of smokers or systematic differences in sniffing between smokers and never-smokers). Given Srivastava et al.'s (1991) observation of twofold plasma nicotine accumulation in never-smokers, however, pharmacokinetic tolerance seems to offer the most parsimonious explanation of the present findings; confirmation awaits studies in which volume of distribution and clearance are directly assessed.

To study pharmacodynamic tolerance without the confound of pharmacokinetic tolerance, we expressed our single bolus data in such a way as to obviate the temporal disassociation (see Porchet et al., 1987) between brain nicotine effect (manifested by the physiological response) and nicotine level in circulation (using peripheral venous levels as an estimate); to do so, we divided peak physiological reactivity by peak nicotine increment (typically reached 5-10 minutes later) for each subject. Our finding of an inverse correlation between sensitivity to nicotine (i.e. reactivity per unit plasma nicotine increment) and previous exposure to nicotine (indicated by baseline cotinine level) in smokers is completely consistent with numerous previous reports (e.g. Perkins et al., 1989; Pomerleau et al., 1983) showing that heavy smokers are significantly less reactive (that is, show greater functional tolerance) to nicotine than light smokers. Extrapolating from these data, we might have expected never-smokers, by virtue of minimal previous exposure, to be substantially more sensitive to a given plasma nicotine concentration than smokers (to a degree that would be readily detectable in comparisons of two groups of 10 subjects). In fact, however, the neversmokers were not much different from smokers in sensitivity to nicotine. These findings are all the more striking because the protocol introduced a bias favoring the observation of greater sensitivity to nicotine in never-smokers, since smokers were minimally deprived and reactivity was measured within the period of influence of acute tolerance (Porchet, Benowitz \& Sheiner, 1988). In a subsequent comparison involving the five male never-smokers in the present study and a matched group of 12 overnight-deprived male smokers (Pomerleau et al., 1992b), the six overnight-deprived light smokers showed greater heart-rate reactivity than the never-smokers, while the six overnight-deprived heavy smokers were more reactive than either light smokers or never-smokers. (Differences fell short of significance).

We note that reactivity for systolic blood pressure in the present study, in contrast to that for heart and diastolic blood pressure, showed some evidence, albeit inconclusive, of being greater in never-smokers than in smokers. Since physiological, subjective, and biochemical responses to nicotine are known to be subject to different types and degrees of tolerance (Hasenfratz, Nil \& Battig, 1990; Perkins, Stiller \& Jennings, 1991), future studies assessing a broader range of modalities will be required to do full justice to the complexity of the differences in sensitivity 
and/or tolerance to nicotine between smokers and never-smokers.

Our findings, though preliminary, raise the possibility that pre-existing differences in sensitivity to nicotine-rather than exposure to nicotine over time - set the stage for patterns of subsequent nicotine use. An implication is that persons destined to become smokers may be more sensitive to nicotine initially, a possibility previously proposed by Russell (1989); the data further suggest that the development of pharmacodynamic tolerance may be an adaptation that reflects magnitude of initial reactions to nicotine (possibly a dampening of sensitivity proportional to disruption of homeostasis). Once smoking patterns are established, the critical difference between smokers and non-smokers may then lie in the degree of pharmacokinetic tolerance developed as a result of nicotine exposure. Further research using larger samples of smokers in different stages of deprivation, administering the same nicotine doses to smokers and never-smokers, and using a true placebo control will be needed to sort out the contribution of steadystate nicotine level prior to sensitivity-test dosing and to confirm the inference that people who are constitutionally more sensitive to nicotine are more vulnerable to nicotine addiction.

\section{Acknowledgements}

Support for this research was provided by the Kughn Clinical Research Center of the University of Michigan (MOI-RR00042) and by a grant to the first author from the National Institute on Drug Abuse (DA06529).

\section{References}

BECKeTT, A. H., GorRod, J. W. \& JENNER, P. (1971) Effect of smoking on nicotine metabolism in vivo in man, fournal of Pharmacy and Pharmacology, 23 (Suppl.), pp. 62S-67S.

Benowrtz, N. L. (1990) Pharmacology of nicotine: Tolerance and kinetics, in: HeNNINGFIELD, J. E. \& STTTZER, M. J. (Eds) New Developments in Nicotinedelivery Systems, pp. 11-12 (Ossining, NY, Cortlandt Communications).

Feyerabend, C., Ings, R. M. J. \& Russeli, M. A. H. (1985) Nicotine pharmacokinetics and its application to intake from smoking, British fournal of Clinical Pharmacology, 19, pp. 239-247.

Hariharan, M., VanNoord, T. \& Greden, J. F.
(1988) A high-performance liquid-chromatographic method for routine simultaneous determination of nicotine and cotinine in plasma, Clinical Chemistry, 34, pp. 724-729.

Hasenfratz, M., NiL, R. \& BatTig, K. (1990) Development of central and peripheral smoking effects over time, Psychopharmacology, 101, pp. 359-365.

Kyeramaten, G. A., Damiano, M. D., Dvorchik, B. H. \& VesELL, E. S. (1982) Smoking-induced changes in nicotine disposition: application of a new HPLC for nicotine and its metabolites, Clinical Pharmacology and Therapeutics, 32, pp. 769-780.

PERKINS, K. A., EPSTEIN, L. H., STILI.ER, R. L., MARKs, B. L. \& JACOB, R. G. (1989) Chronic and acute tolerance in the heart rate effects of nicotine, Psychopharmacology, 97, pp. 529-534.

Perkins, K. A., Stiller, R. L. \& Jennings, J. R. (1991) Acute tolerance to the cardiovascular effects of nicotine, Drug and Alcohol Dependence, 29, pp. 77-85.

Pomerleau, O. F., Fertig, J. \& Shanahan, S. O. (1983) Nicotine dependence in cigarette smoking: empirically-based, multivariate model, Pharmacology Biochemistry \& Behaviour, 19, pp. 291-299.

Pomerleau, O. F., Flessland, K. A., Pomerleau, C. S. \& Haruharan, M. (1992a) Controlled dosing of nicotine via an intranasal nicotine aerosol delivery device (INADD), Psychopharmacology, 108, pp. 519-526.

Pomerleau, O. F., Pomerleau, C. S., Cameron, O. G. \& Hariharan, M. (1992b) Sensitivity to nicotine in smokers and never-smokers, Proceedings of the 54th Annual Scientific Meeting, Committee on Problems of Drug Dependence, Inc. (NIDA Research Monograph, USDHHS).

Pomerleau, O. F, Pomerleau, C. S. \& Rose, J. E. (1989) Controlled dosing of nicotine: problems and progress, Annals of Behavioral Medicine, 11, pp. $158-163$

Porchet, H. C., Benowrtz, N. L., Sheiner, L. B. \& Copel.and, J. R. (1987) Apparent tolerance to the acute effect of nicotine results in part from distribution kinetics, fournal of Clinical Investigation, 80, pp. 1466-1471.

Porchett, H. C., Benowitz, N. L. \& Sheiner, L. B. (1988) Pharmacodynamic model of tolerance: application to nicotine, The fournal of Pharmacology and Experimental Therapeutics, 224, pp. 231-236.

RuSSELL, M. A. H. (1989) Subjective and behavioural effects of nicotine in humans: some sources of individual variation, in: NORDBERG, A., FuxE, K., Holmstedt, B. \& Sundwall, A. (Eds) Nicotinic Receptors in the CHS: Their Role in Synaptic Transmission, pp. 289-302 (Amsterdam, Elsevier).

Srivastava, E. D., Russel. , M. A. H., Feyerabend, C., Masterson, J. G. \& Rhodes, J. (1991) Sensitivity and tolerance to nicotine in smokers and non-smokers, Psychopharmacology, 105, pp. 63-68.

USDHHS (1988) The Health Consequences of Smoking: Nicotine Addiction (1988 Report of the Surgeon General), p. 53 (Rockville, MD, Public Health Service, Office on Smoking and Health). 
This document is a scanned copy of a printed document. No warranty is given about the accuracy of the copy. Users should refer to the original published version of the material. 